\title{
Colon or Rectal Stent Positioning for Advanced Cancer Influences Quality of Life: A Critical Point of View
}

\author{
ENRICO FIORI ${ }^{1}$, DANIELE CROCETTI ${ }^{1}$, PAOLO SAPIENZA ${ }^{1}$, MICHELANGELO MICCINI ${ }^{1}$, \\ ROBERTO CIROCCHI ${ }^{2}$, ANTONIO V. STERPETTI ${ }^{1}$, FRANCESCA DE FELICE ${ }^{3}$, SILVANO COSTI $^{4}$, \\ GIOIA BRACHINI ${ }^{1}$, ANDREA MINGOLI ${ }^{1}$, ANTONIETTA LAMAZZA ${ }^{1}$ and GIORGIO DE TOMA ${ }^{1}$ \\ ${ }^{1}$ Department of Surgery "Pietro Valdoni", "Sapienza" University of Rome, Rome, Italy; \\ ${ }^{2}$ Department of Surgical and Biomedical Sciences, Perugia University, Terni, Italy; \\ ${ }^{3}$ Department of Radiology, Radiotherapy, Oncology and Pathology, "Sapienza" University of Rome, Rome, Italy; \\ ${ }^{4}$ Department of Economics and Finance, LUISS Guido Carli, Rome, Italy
}

\begin{abstract}
Background/Aim: Endoluminal self-expanding metallic stents (SEMS) may overcome the risk of mortality and morbidity of acute intestinal obstruction because of stage IV colon $(C C)$ or rectal $(R C)$ cancer. We evaluated the QoL in these groups of patients. Patients and Methods: Forty-eight patients were enrolled in a prospective longitudinal cohort single-center trial to undergo SEMS positioning. Twenty-five patients had a CC and $23 R C$. Karnofsky performance scale, Visual Analogue Scale and the EQ-5D- 5L $L^{T M}$ questionnaire were administered before treatment and at 1,3 and 6 months. Results: Harmonized to the Italian population, the index values showed a statistically significant deterioration of the QoL in patients with RC when compared to those with CC at 1-, 3- and 6-months (1 month: $p=0.001 ; 3$ - month: $p=0.001 ; 6$-month: $p=0.045)$. Similarly, Visual Analogue Scale showed variations at 1 - $(p=0.008), 3-(p=0.001)$ and 6-months $(p=0.020)$. Rectal stent deployment was the only independent predictor for a worse QoL in all domains ( $p<0.017 ; \mathrm{OR}=0.196 ; 95 \% C I=0.51$ 0.749). Conclusion: Patients affected with stage IV CC had a better QoL after SEMS placement when compared to those affected with $R C$. The persistency of the primary tumor at the rectal level, even if irradiated, might negatively affect QoL.
\end{abstract}

When the tumor is located at or distal to the splenic flexure, acute intestinal obstruction is the presentation of colorectal cancer in $7-30 \%$ of cases (1). The risk of impending bowel

This article is freely accessible online.

Correspondence to: Daniele Crocetti, MD, Ph.D., Department of Surgery "Pietro Valdoni", "Sapienza" University of Rome, Viale del Policlinico 155, 00166 Rome, Italy. E-mail: daniele.crocetti@uniroma1.it

Key Words: Advanced colorectal cancer, endoscopic stent positioning, surgical resection, quality of life (QoL). necrosis and colonic perforation caused by acute intestinal obstruction requires a prompt surgical bowel decompression. The therapeutic options include tumor resection with primary anastomosis or a two- or three-stage procedures (2). After an emergent surgery the mortality and major complications reach $15 \%$ to $20 \%$, and $50 \%$, respectively, whereas the mortality ranges between 0 and $9 \%$, and major complications between 5 and 20\% when patients undergo elective surgery (3). Endoluminal self-expanding metallic stents (SEMS) positioning in the treatment of malignant gastrointestinal obstruction may overcome the risk of mortality and morbidity because it is an effective and safe option to open surgery (4).

Theoretically, SEMS placement might be the preferred treatment for patients affected with unresectable stage IV colorectal cancer presenting with acute and subacute obstruction symptoms (3). SEMS is able to relieve the obstruction and offers many advantages, such as converting an emergent operation to an elective operation (5). The appropriateness of the different therapeutic options in patients affected with an advanced colorectal cancer should be measured with the quality of life (QoL). We recently demonstrated that during follow-up SEMS placement has a bimodal fluctuation pattern in terms of QoL. Stent positioning seems, in fact, to have better results at 1-month whereas at 6-months significantly worsened when compared to patients undergoing surgical resection (6). This study included patients affected with a stage IV colorectal cancer, but it was unable to elucidate the eventual differences in QoL related to SEMS positioning in the colon or rectal tract. We are well aware that QoL of patients affected with advanced rectal cancer may be negatively influenced by the persistency of symptoms after stent positioning: this treatment modality is able to solve tumor obstruction, but it is unable to relief symptoms from nerve compression or invasion. In association with radiation therapy may reduce this symptomatology $(7,8)$. 
In the present study we aimed to evaluate, in a prospective longitudinal cohort single-center trial, the QoL of advanced colon cancer patients treated with SEMS placement compared to those with advanced rectal cancer.

\section{Patients and Methods}

All patients presenting with stage IV colon or rectal cancer at our Institution from February 2013 to January 2020 were enrolled into this prospective longitudinal cohort trial. All patient' data were handled according to the principles of the Declaration of Helsinki and a formal ethic approval from our Institutional Research Committee was obtained. The protocol was properly registered at a public trial registry, www.clinicaltrials.gov (Trial identifier NCT03451643). A written informed consent for the treatment and the analysis of data for scientific purposes was obtained from all patients. All patients were acknowledged of their terminal disease with the assistance of a psychologist.

A computerized database was then created to prospectively collect all clinical, pathological, intra- and post-operative outcomes, Karnofsky performance status scale (9), Visual Analogue Scale (10), quality of life (EQ-5D ${ }^{\mathrm{TM}}$ ) (11) and long-term survival.

Inclusion criteria were: age less than 85 years, pre-treatment histological diagnosis of colon or rectal adenocarcinoma, computed tomography (CT), adjuvant-neoadjuvant radio-chemotherapy regimen, symptoms of subacute large bowel obstruction (defined as continued passage of flatus and/or feces beyond 6-12 h after the onset of symptoms namely colicky abdominal pain, vomiting and abdominal distension relieving with conservative treatment), lumen reduction ranging between $70 \%$ and $99 \%$ at colonoscopy.

Criteria for exclusion were a white blood cell count less than $4,000 / 1$, platelet count less than $70,000 / 1$, patients with renal failure (i.e. albumin to creatinine ratio $>30 \mathrm{mg} / \mathrm{mmol}$ and estimated glomerular filtration rate $<30-44 \mathrm{ml} / \mathrm{min} / 1.73 \mathrm{~m}^{2}$ ), patients with major alterations of liver function tests $(i . e$. total bilirubin $>25.6$ $\mu \mathrm{mol} / 1$, AST $>5 \mathrm{U} / 1$, ALT $>5 \mathrm{U} / 1$, PT-INR $>1.5$ ).

Out of 61 patients presenting with Stage IV colon or rectal cancer and symptoms of subacute large bowel obstruction, 48 were enrolled in the present trial. The remaining 13 patients were excluded from the study because of serum bilirubin levels above $25.6 \mu \mathrm{mol} / \mathrm{l}$ ( 5 patients), low platelet and white blood cell count (6 patients), and renal insufficiency ( 2 patients). In 4 patients there were more than one of the above-mentioned reasons to be excluded from the study and 3 of them also refused to have surgery. Twenty-five (52\%) patients who were affected by advanced stage IV colon cancer formed the colon cancer group (CC) and 23 (48\%) with advanced stage IV rectal cancer formed the rectal cancer group (RC).

Endoscopic procedure. Briefly, our endoscopic procedure has been previously described (6). All patients had one stent placed but in 2 patients two stents were required.

Karnofsky performance scale and Quality of life (QoL) assessment. Briefly, the functional status before SEMS positioning and reclassification after its deployment was analyzed with the Karnofsky performance scale (9). The EQ-5D-5 $\mathrm{L}^{\mathrm{TM}}$ questionnaire (CEuroQol Group, Rotterdam, The Netherlands) (11) was administered before SEMS positioning and thereafter at 1-, 3- and 6-months according to our previously described methods (6) and the results adapted to the general population in Italy matched for age
(11). Furthermore, to help patients say properly respond to questions regarding their health state, a visual analog scale (EQ-VAS ${ }^{\mathrm{TM}}$ ) (10) was administered.

Follow-up evaluation. Patients were followed-up on outpatient basis every month. Hematochemical tests, abdominal CT scan and chest $\mathrm{X}$-ray were performed every three months for the first year, and thereafter every year.

Statistical analysis. Our data were analyzed using the SPSS Ver. 25.0.0.2 software (SPSS Chicago, IL, USA) for MacOS High Sierra ver. 10.13.4 (Apple Inc. 1983-2018 Cupertino, CA, USA). Due to sample sizes, non-parametric tests were applied. The MannWhitney $U$-test was used to analyze the continuous variables whereas the Chi-square test or the Fisher's exact test explored the categorical variables. Due to the heterogeneity of the sample, data were expressed as mean \pm standard deviation, median, interquartile range (IQR) and mode (12). Actuarial survival rate was assessed by the Kaplan-Meier method at 1-year. Standard error (SE) of survival rate was estimated for each censored case. Actuarial survival was limited at 1-year because analysis of longer time period was statistically inappropriate for the small number of patients and the consequent high standard deviations. Logistic regression (forward stepwise method) analysis was used to identify factors affecting the areas of QoL investigation and was computed at the end of the study (6-month). Separate logistic regression model was used for the EQ$5 \mathrm{D}-5 \mathrm{~L}^{\mathrm{TM}}$ questionnaire and the visual analog scale. The following variables were used for logistic regression analysis: age, gender, marital status (married, divorced widowed), social situation (upper, upper-middle, middle, working and lower social classes), level of education, clinical data, neoadjuvant and adjuvant radiochemoradiation therapy, SEMS deployment in the colon or rectum, and postoperative complications. The 5 areas of investigation were dichotomized with a cut-off value of 15 ; specifically, 3 was the cutoff value for each domain. The visual analog scale was dichotomized with a cut-off value of 51 . Differences with $\alpha$-level of $<0.05$ were considered statistically significant.

\section{Results}

Demographics and clinical findings. Thirty-one (65\%) patients were males and 17 (35\%) females and our population had a mean age at presentation of 76 9 years (min. 44-max. 89; median 77; IQR=6; mode 80). Table I summarizes the demographic and clinical data of our series. There were no significant differences among the two groups. Marital and social status were similar among the groups. Specifically, 35 (73\%) were married, 7 (15\%) divorced and 6 (12\%) widowed and no differences among the groups were recorded. Two (4\%) patients defined their social status as appertaining to the upper, $4(8 \%)$ to the upper-middle, $20(42 \%)$ to the middle, $19(40 \%)$ to the working and $3(6 \%)$ to the lower classes. The level of education was similar, and, specifically the majority of them (29-60\%) had a basic education (primary, intermediate and secondary) whereas 19 (40\%) had college or master education.

Early results. There were no postoperative mortality and major complications within 30 days. There was a significantly 
Table I. Demographics and clinical data.

\begin{tabular}{lccc}
\hline & CC & RC & Significance \\
\hline Number & 25 & 23 & $p$-Value \\
\hline Mean age (SD; IQR; Median; Mode) & $76(9 ; 7 ; 77 ; 80)$ & $76(9 ; 6 ; 77 ; 80)$ & 0.943 \\
Gender (M/F) & $17 / 8$ & $14 / 9$ & 0.764 \\
Total bilirubin ( $\mu$ mol/l) & $22(3)$ & $4(0.2)$ & 0.563 \\
AST (U/l) & $4(0.3)$ & $4(.03)$ & 0.748 \\
ALT (U/l) & $5(0.2)$ & $1.0(0.2)$ & 0.427 \\
PT-INR & $0.8(0.2)$ & 2 & 0.612 \\
Ascites & 2 & 4 & 0.875 \\
Liver metastasis & 5 & 7 & 0.773 \\
Less than 3 & 5 & 11 & 0.263 \\
More than 3 & 8 & & \\
Pulmonary metastases (presence or absence) & 8 & \\
\hline
\end{tabular}

Between brackets standard deviation; SD: Standard deviation; IQR: interquartile range; AST: aspartate aminotransferase; ALT: alanine transaminase; PT-INR: prothrombin time-international normalized ratio.

higher incidence of minor complications in $\mathrm{RC}$ as compared to $\mathrm{CC}(p=0.046) ; 4(17 \%)$ patients had, in fact, rectal bleeding for 1-2 days, which resolved spontaneously.

Overall mean length of stay was $2 \pm 1$ days (min. 1 - max. 5; mode $1, \mathrm{IQR}=2$ ) and there were no statistical differences among the two Groups $(p=0.869 ; 95 \% \mathrm{CI}=-0.753-0.638)$.

Long-term results. No patients were lost to follow-up (mean 9 \pm 3 months; min. 4-max. 18; median 9; mode 9, IQR=4). There were no major or life-threatening complications related to chemotherapy but $3(6 \%)$ patients ( 2 patients in $\mathrm{CC}$ and 1 in RC) stopped chemotherapy because of a significant deterioration of their liver function after the first cycle. Symptoms, potentially related to chemotherapy (fatigue, partial hair loss, decreasing liver function) were common (32-67\% patients), and equally distributed in the two groups (18 in CC and $14 \mathrm{RC}$ ).

One-year actuarial survival rate of $\mathrm{CC}$ was $22 \%(\mathrm{SE}=0.10$; $95 \% \mathrm{CI}=6.162-11.838)$ whereas in $\mathrm{RC}$ was $42 \%(\mathrm{SE}=0.15$; $95 \% \mathrm{CI}=9.278-14.722)$.

Karnofsky performance scale and Quality of Life (QoL). Preoperative Karnofsky performance scale classified patients' functional impairment showing no significant differences among the two groups $(73 \pm 14$ and $73 \pm 13$, respectively, for CC and RC; $p=0.951 ; 95 \% \mathrm{CI}=-8.17405-7.68709)$. Similarly, the Karnofsky performance scale at 1-, 3- and 6-month showed no statistical differences between CC and RC (1-month: 60土11 and $62 \pm 12$, respectively, for $\mathrm{CC}$ and $\mathrm{RC}, p=0.451$; $95 \% \mathrm{CI}=-$ 9.39395-4.24612; 3-month: $60 \pm 9$ and 59 \pm , respectively, for $\mathrm{CC}$ and $\mathrm{RC}, p=0.581 ; 95 \% \mathrm{CI}=-3.41311-6.02181$; 6-month: $55 \pm 8$ and $58 \pm 7$, respectively for $\mathrm{CC}$ and $\mathrm{RC}, p=0.255$; 95\% CI=-7.50301-2.04847). Harmonized to the Italian population, the preoperative index values were similar among the groups $(0.35 \pm 0.08$ and $0.34 \pm 0.11$, respectively for $\mathrm{CC}$ and $\mathrm{RC}, p=0.823 ; 95 \% \mathrm{CI}=-0.051892-0.064887)$. Conversely, at $1-$ , 3- and 6-month, index values showed a statistically significant deterioration of the QoL in patients of $\mathrm{RC}$ when compared to those of CC ( 1 month: $0.33 \pm 0.08$ and $0.10 \pm 0.11$, respectively, for $\mathrm{CC}$ and $2, p=0.001 ; 95 \% \mathrm{CI}=0.162891-0.286386$; 3 - month: $0.26 \pm 0.09$ and $0.10 \pm 0.10$, respectively, for $\mathrm{CC}$ and $\mathrm{RC}$, $p=0.001$; $95 \% \mathrm{CI}=0.98630-0.206024$; 6-month: $0.51 \pm 0.18$ and $0.39 \pm 0.20$, respectively, for $\mathrm{CC}$ and $\mathrm{RC} ; \quad p=0.045$; $95 \% \mathrm{CI}=0.003138-0.235979)$. Preoperative visual analog scale was similar among CC and RC (74 \pm 13 and $74 \pm 12$, respectively for $\mathrm{CC}$ and $\mathrm{RC} ; \quad p=0.933 ; 95 \% \mathrm{CI}=-7.75168-7.12560)$. Conversely, significant variations among the two groups of patients in the postoperative period at $1-(65 \pm 11$ and $56 \pm 9$, respectively for $\mathrm{CC}$ and $\mathrm{RC}$; $p=0.008$; 95\% CI $=2.27223$ -

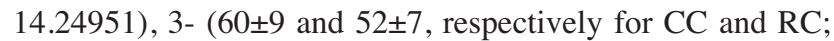
$p=0.001 ; 95 \% \mathrm{CI}=3.25368-12.76372)$ and 6-month $(55 \pm 8$ and $49 \pm 6$, respectively, for CC and RC, $p=0.020$; $95 \% \mathrm{CI}=0.91955$ 10.17136) were observed.

Factors influencing QoL. In the EQ-5D-5L ${ }^{\mathrm{TM}}$ questionnaire, the independent predictor of a worse QoL in all domains was location of SEMS deployment. Specifically, patients who had a rectal stent deployment experienced a worse QoL with respect to those who had a colon stent deployment $(p<0.017$; $\mathrm{OR}=0.196 ; 95 \% \mathrm{CI}=0.51-0.749)$. Conversely, none of the variables inserted into the model identified independent factors influencing QoL on the visual analog scale.

\section{Discussion}

In patients with limited life-expectancy due to unresectable colon or rectal tumors associated with metastatic disease, SEMS deployment seems to be effective in relieving 
obstructive symptoms and preventing the need for general anesthesia or emergency surgery (13-15), whereas the discomfort of this procedure is minimal (6). Furthermore, we recently observed that the QoL of advanced colorectal cancer patients improves significantly because it permits a better relationship with their relatives and allows a regular social life compared to palliative diverting surgery $(14,15)$. Disappointingly, the QoL had a bimodal fluctuation pattern at 1-month it was better in patients treated with stent but at 6months it was significantly better in patients who underwent surgical resection (6). These figures are very interesting, and intriguing, but it was hard to find a proper explanation for this difference. However, in our previous study (6) we included patients affected with unresectable stage IV colon or rectal cancer with symptoms of obstruction without any distinction regarding the location of the primary tumor.

The present study was undertaken to answer the question whether the location of the stent might have a role in the worst QoL of patients at a mid-term follow-up and, therefore, we first compared the QoL of patients who had SEMS placement at the colon or rectal level.

The present data showed a significant worse QoL of patients who underwent SEMS positioning for rectal tumor when compared to those who had a colon stent deployment at 1-, 3- and 6-month follow-up. Multivariate analysis confirmed that the only independent predictor of a poor QoL in all domains of the questionnaire was the location of SEMS deployment.

These data necessitate a deep reflection and probably a change in the approach of patients affected with an advanced rectal tumor. Three important aspects should be highlighted: firstly, rectal nerve anatomy, which follows a completely different pathway of innervation compared to the colon, consists of a large network of fibers that can be compressed and cause per se more symptoms $(7,8)$ (tenesmus, abdominal and rectal pain during and after evacuation, genito-urinary related symptoms such as urinary urgency or pollakiuria) than the colon segment, and this occurrence is clearly independent from the stent deployment and it might be even worsened by the insertion of the stent. Therefore, the differences in the nerve network between these two anatomical regions might explain the divergencies in QoL among the two groups of patients. Secondly, in our series radiotherapy apparently had a marginal role in improving the QoL of patients with advanced rectal cancer (16-18). Thirdly, since the improvement of the QoL drives our strategy for treatment, these results might suggest that, whenever it is possible, a surgical approach may be preferable to a stent positioning in advanced rectal cancer.

Interestingly, although colon or rectal SEMS positioning might be risky because of the eventual serious complications, including perforation, we only recorded some minor complications $(3,5)$. We recommend stent positioning to be performed by experienced staff personnel with a proper preoperative preparation (nasogastric tube and fasting with correction of the fluid and electrolytes imbalance with the intent to reduce the caliber mismatch from above and below the tumor stricture) and selection of the patients amenable of this procedure excluding patients with residual gross colonic dilatation, in whom there is a persistent significant risk of perforation and/or ischemia, and can undergo conventional surgery $(3,5,13,19-29)$.

We are well aware that our study has several limitations. The enrollment of patients was limited by the fact that this was a single-center study, thus having a significant heterogeneity in the presentation of stage IV colorectal cancer. Furthermore, we did not compare any of the two groups with a matched group of patients undergoing a primary tumor surgical resection. Conversely, our study has some strengthens i.e. no patients were lost at follow-up, and all questionnaires with formally validated scales were completed by all patients.

In conclusion, patients affected with stage IV colon cancer have better QoL after SEMS placement when compared to those who undergo SEMS positioning for stage IV rectal cancer. We hypothesized that the persistency of the primary tumor at the rectal level even if irradiated might negatively affect the QoL if SEMS is positioned.

\section{Conflicts of Interest}

The Authors have no conflicts of interest to declare regarding this study.

\section{Authors' Contributions}

Enrico Fiori: Conception, design and data analysis; Daniele Crocetti: Conception, design and writing the manuscript; Paolo Sapienza: Conception, design and writing the manuscript; Antonietta Lamazza: Analysis and interpretation of data; Michelangelo Miccini: Data analysis; Roberto Cirocchi: Conception; Antonio V. Sterpetti: Conception and design; Francesca De Felice: Conception and writing the manuscript: Silvano Costi: Data analysis; Gioia Brachini: Collection of data; Andrea Mingoli: Interpretation of data; Giorgio De Toma: Conception and design.

\section{References}

1 Cirocchi R, Farinella E, Trastulli S, Desiderio J, Listorti C, Boselli C, Parisi A, Noya G and Sagar J: Safety and efficacy of endoscopic colonic stenting as a bridge to surgery in the management of intestinal obstruction due to left colon and rectal cancer: A systematic review and meta-analysis. Surg Oncol 22(1): 14-21, 2013. PMID: 23183301. DOI: 10.1016/j.suronc.2012.10.003

2 Bonin EA and Baron TH: Update on the indications and use of colonic stents. Curr Gastroenterol Rep 12(5): 374-382, 2010. PMID: 20703837. DOI: 10.1007/s11894-010-0136-x

3 Lamazza A, Fiori E, Schillaci A, Sterpetti AV and Lezoche E: Treatment of anastomotic stenosis and leakage after colorectal 
resection for cancer with self-expandable metal stents. Am J Surg 208(3): 465-469, 2014. PMID: 24560186. DOI: 10.1016/j.amjsurg.2013.09.032

4 Saida Y: Current status of colonic stent for obstructive colorectal cancer in Japan; A review of the literature. J Anus Rectum Colon 3(3): 99-105, 2019. PMID: 31583324. DOI: 10.23922/jarc.2019009

5 Lamazza A, Fiori E, Schillaci A and Sterpetti AV: A new technique for placement of a self-expanding metallic stent (SEMS) in patients with colon rectal obstruction: A prospective study of 43 patients. Surg Endosc 27(3): 1045-1048, 2013. PMID: 23052503. DOI: 10.1007/s00464-012-2522-y

6 Fiori E, Lamazza A, Sterpetti AV, Crocetti D, DE Felice F, DI Muzio M, Mingoli A, Sapienza P and DE Toma G: Quality of life for patients with incurable stage IV colorectal cancer: Randomized controlled trial comparing resection versus endoscopic stenting. In Vivo 33(6): 2065-2070, 2019. PMID: 31662539. DOI: 10.21873 /invivo. 11705

7 Coco C, Cogliandolo S, Riccioni ME, Ciletti S, MarinoConsentino L, Coppola R and Picciocchi A: Use of a selfexpanding stent in the palliation of rectal cancer recurrences. A report of three cases. Surg Endosc 14(8): 708-711, 2000. PMID: 10954814. DOI: $10.1007 / \mathrm{s} 004640000198$

8 Fiori E, Crocetti D, Lamazza A, DE Felice F, Sterpetti AV, Irace L, Mingoli A, Sapienza P and DE Toma G: Is low inferior mesenteric artery ligation worthwhile to prevent urinary and sexual dysfunction after total mesorectal excision for rectal cancer? Anticancer Res 40(8): 4223-4228, 2020. PMID: 32727748. DOI: 10.21873 /anticanres.14423

9 Schag CC, Heinrich RL and Ganz PA: Karnofsky performance status revisited: Reliability, validity, and guidelines. J Clin Oncol 2(3): 187-193, 1984. PMID: 6699671. DOI: 10.1200/JCO. 1984.2.3.187

10 Faiz KW: VAS - visual analog scale. Tidsskr Nor Laegeforen 134(3): 323, 2014. PMID: 24518484. DOI: 10.4045/tidsskr. 13.1145

11 Scalone L, Cortesi PA, Ciampichini R, Belisari A, D’Angiolella LS, Cesana G and Mantovani LG: Italian population-based values of EQ-5D health states. Value Health 16(5): 814-822, 2013. PMID: 23947975. DOI: 10.1016/j.jval.2013.04.008

12 Whitley E and Ball J: Statistics review 1: Presenting and summarising data. Crit Care 6(1): 66-71, 2002. PMID: 11940268. DOI: $10.1186 / \mathrm{cc} 1455$

13 Lamazza A, Fiori E, De Masi E, Scoglio D, Sterpetti AV and Lezoche E: Self-expanding metal stents for treatment of anastomotic complications after colorectal resection. Endoscopy 45(6): 493-495, 2013. PMID: 23733731. DOI: 10.1055/s-00321326488

14 Scomparin RC, Martins BC, Lenz L, Bento LH, Marques CS, Safatle-Ribeiro A, Ribeiro U Jr, Nahas SC and Maluf-Filho F: Long-term survival analysis after endoscopic stenting as a bridge to surgery for malignant colorectal obstruction: Comparison with emergency diverting colostomy. Clinics (Sao Paulo) 75: e2046, 2020. PMID: 33206763. DOI: 10.6061/clinics/2020/e2046

15 Lamazza A, Fiori E, Sterpetti AV, Schillaci A, De Cesare A and Lezoche E: Endoscopic placement of self-expandable metallic stents for rectovaginal fistula after colorectal resection: A comparison with proximal diverting ileostomy alone. Surg Endosc 30(2): 797-801, 2016. PMID: 26017913. DOI: $10.1007 / \mathrm{s} 00464-015-4246-2$
16 De Felice F, Crocetti D, Parisi M, Maiuri V, Moscarelli E, Caiazzo R, Bulzonetti N, Musio D and Tombolini V: Decision tree algorithm in locally advanced rectal cancer: An example of over-interpretation and misuse of a machine learning approach. J Cancer Res Clin Oncol 146(3): 761-765, 2020. PMID: 31784835. DOI: 10.1007/s00432-019-03102-y

17 Kosmala R, Fokas E, Flentje M, Sauer R, Liersch T, Graeven U, Fietkau R, Hohenberger W, Arnold D, Hofheinz RD, Ghadimi M, Ströbel P, Staib L, Grabenbauer GG, Folprecht G, Kirste S, Uter W, Gall C, Rödel C, Polat B and of the German Rectal Cancer Study Group.: Quality of life in rectal cancer patients with or without oxaliplatin in the randomised CAO/ARO/AIO04 phase 3 trial. Eur J Cancer 144: 281-290, 2021. PMID: 33383348. DOI: 10.1016/j.ejca.2020.11.029

18 De Felice F, Crocetti D, Maiuri V, Parisi M, Marampon F, Izzo L, De Toma G, Musio D and Tombolini V: Locally advanced rectal cancer: Treatment approach in elderly patients. Curr Treat Options Oncol 21(1): 1, 2020. PMID: 31927649. DOI: 10.1007/s11864-019-0692-8

19 Fiori E, Crocetti D, Lamazza A, DE Felice F, Tarallo M, Sterpetti AV, Mingoli A, Sapienza P and DE Toma G: Resection or stenting in the treatment of symptomatic advanced metastatic rectal cancer: A dilemma. Anticancer Res 39(12): 6781-6786, 2019. PMID: 31810943. DOI: 10.21873/anticanres. 13893

20 Guerra F, Crocetti D, Giuliani G and La Torre F: Surgery for anorectal strictures following stapled procedures. Colorectal Dis 17(3): 266-268, 2015. PMID: 25603879. DOI: 10.1111/ codi. 12904

21 Hanaoka M, Ogo T, Kawamura Y, Miura T, Aburatani T, Sugimoto H, Hoshino N, Yauchi T, Nishioka Y and Kawano T: Self-expandable metal stent as a bridge to surgery for colorectal cancer: Safety and oncological outcomes. In Vivo 34(3): 13251331, 2020. PMID: 32354926. DOI: 10.21873/invivo.11909

22 Fiori E, Crocetti D, Lamazza A, DE Felice F, Scotti GB, Sterpetti AV, Mingoli A, Sapienza P and DE Toma G: Defecatory dysfunction after colon cancer resection: The role of inferior mesenteric artery tie. Anticancer Res 40(5): 2969-2974, 2020. PMID: 32366450. DOI: 10.21873/anticanres.14276

23 Crocetti D, Cavallaro G, Tarallo MR, Chiappini A, Polistena A, Sapienza P, Fiori E and De Toma G: Preservation of left colic artery with lymph node dissection of IMA root during laparoscopic surgery for rectosigmoid cancer. Results of a retrospective analysis. Clin Ter 170(2): e124-e128, 2019. PMID: 30993308. DOI: 10.7417/CT.2019.2121

24 Berselli M, Borroni G, Livraghi L, Quintodei V, Sambucci D, Cortelezzi C, Segato S, Carcano G and Cocozza E: Laparoscopic approach to large bowel neoplastic obstruction after SelfExpandable-Metal-Stent (SEMS) placement. Surg Laparosc Endosc Percutan Tech 29(2): 133-137, 2019. PMID: 30629036. DOI: $10.1097 /$ SLE.0000000000000623

25 Polistena A, Cavallaro G, D'Ermo G, Paliotta A, Crocetti D, Rosato L and De Toma G: Clinical and surgical aspects of high and low ligation of inferior mesenteric artery in laparoscopic resection for advanced colorectal cancer in elderly patients. Minerva Chir 68(3): 281-288, 2013. PMID: 23774093.

26 Bocca B, Lamazza A, Pino A, De Masi E, Iacomino M, Mattei D, Rahimi S, Fiori E, Schillaci A, Alimonti A and Forte G: Determination of 30 elements in colorectal biopsies by sector field inductively coupled plasma mass spectrometry: Method development and preliminary baseline levels. Rapid Commun 
Mass Spectrom 21(11): 1776-1782, 2007. PMID: 17486673. DOI: $10.1002 / \mathrm{rcm} .3016$

27 Alimonti A, Bocca B, Lamazza A, Forte G, Rahimi S, Mattei D, Fiori E, Iacomino M, Schillaci A, De Masi E and Pino A: A study on metals content in patients with colorectal polyps. J Toxicol Environ Health A 71(5): 342-347, 2008. PMID: 18214808. DOI: $10.1080 / 15287390701839133$

28 Bononi M, De Cesare A, Stella MC, Fiori E, Galati G, Atella F, Angelini M, Cimitan A, Lemos A and Cangemi V: Isolated intestinal neurofibromatosis of colon. Single case report and review of the literature. Dig Liver Dis 32(8): 737-742, 2000. PMID: 11142587. DOI: 10.1016/s1590-8658(00)80340-0
29 Fiori E, Pozzessere C, Lamazza A, Leone G, Borrini F, Schillaci A and Mingazzini P: Endoscopic treatment of ganglioneuroma of the colon associated with a lipoma: A case report. J Med Case Rep 6: 304, 2012. PMID: 22978818. DOI: 10.1186/1752-19476-304

Received February 5, 2021 Revised March 1, 2021 Accepted March 2, 2021 